\title{
Digital Simulation as Learning Aid for Heat Flow in Solid Theoretical Understanding
}

\begin{tabular}{l}
\hline Received \\
16 July 2020 \\
\\
Revised \\
08 August 2020 \\
\\
Accepted for Publication \\
15 August 2020 \\
Published \\
27 August 2020 \\
\end{tabular}

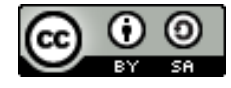

This work is licensed under a Creative Commons AttributionShareAlike 4.0 International License

\author{
I M Sutjahja ${ }^{1^{*}}$, S Assegaf ${ }^{1}$, dan S Wonorahardjo ${ }^{2}$ \\ 1. Department of Physics, Faculty of Math and Science, Institut Teknologi Bandung, Jl. Ganesha \\ 10, Bandung, 40132, Indonesia. \\ 2. Architecture Program, School of Architecture and Urban Planning, Institut Teknologi Bandung, \\ Jl. Ganesha 10, Bandung, 40132, Indonesia. \\ *Email: inge@fi.itb.ac.id
}

\begin{abstract}
Understanding the physical phenomena is extremely aided by digital simulations for understanding physical phenomena that occur, especially for students in the digital era and in this new-normal period. This paper describes heat conduction in solids using the Energy2D program, starting from general formulations for heat conduction from conductors to general solids that show the mechanism of heat conduction as a diffusion process. The thermal diffusivity parameter determines heat diffusion as the ratio between thermal conductivity and multiplication between density and thermal capacity. From the practical side, heat conduction is ordinary using thermal resistance (R-value) that combines the dimensions of the material in the direction of heat flow and thermal conductivity. By taking an analogy with Ohm's law for electrical circuits, it can be determined the equivalent resistance of several thermal resistance of the material that is composed in series or parallel. A good understanding of the heat transport process in buildings is needed for the development of technologies required for the comfort of human life and energy conservation.

Keywords: Thermal diffusion, digital simulation, thermophysical.
\end{abstract}

\section{Introduction}

Theoretical understanding of natural physical phenomenon requires a long period, involving the observer's experiences and logic. Heat flow in solid is one of the physical phenomena with sophisticated understanding. For instance, the conduction heat flow in a building's wall consists of some layers, such as weather shield paint, plaster layer that is commonly made from concrete, wall substance that generally fulfil load bearer criteria, inner plaster layer, as well as inner protective paint. The material of each layer has different thermal features so that the system performance of a building's wall is incomprehensible [1]. On the other hand, the heat flow in the building's wall is essential since it is related to the building's energy consumption [2], [3], along with the damage of the surrounding thermal environment [4].

Heat flow understanding using the experimental method aims to explain the process of that heat flow. That method is frequently used by scientists and engineers to confirm the phenomena. Besides, the results of that experiment can be used as input or validation of an estimation method, so that it generates various mathematical models. Engineering schools use that pragmatic approach and have validated that the approach carries advancement. By using that mathematical model, the phenomena can be better recognized and utilized to estimates non-existent conditions. Additionally, this method enables an experiment with reasonable cost and maximum result.

Both experimental and mathematical approaches possess benefits and weaknesses that complete each other in aiding the understanding of heat flow in solid physical phenomena and in the development of technology, as illustrated in Figure 1. The heat flow process cannot be directly observed in the experimental method that generally involves some temperature sensors. This process is indirectly comprehended in this approach, as well as in the mathematical approach. 


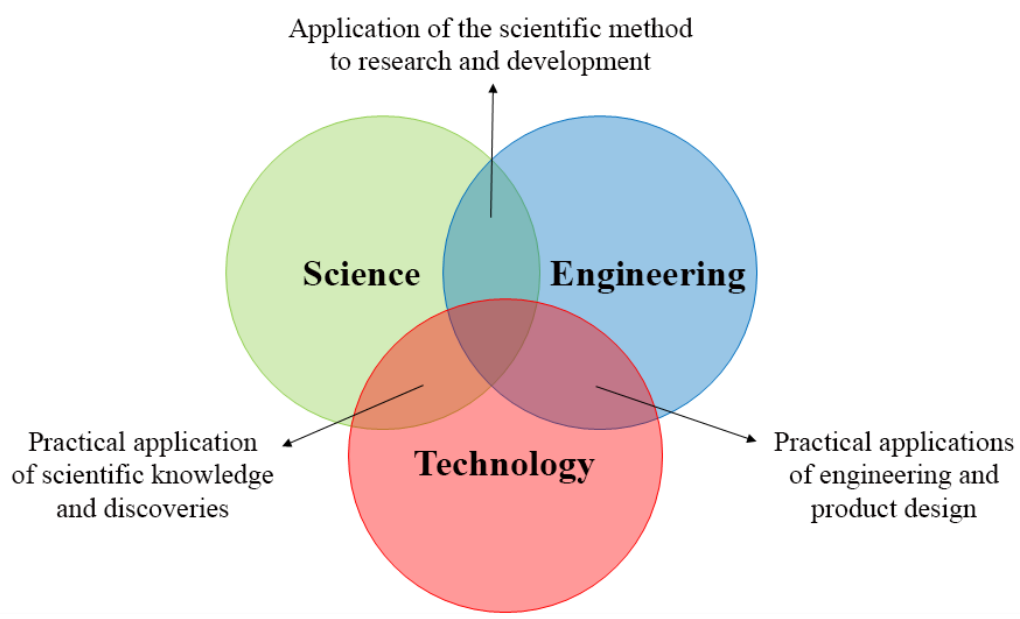

Figure 1. The relation between science, technology, and engineering.

In addition to the heat transfer, the role of solid characteristics, such as specific heat, density, and thermal conductivity is also indirectly comprehended. Conventionally, those understandings are obtained through mathematical models. However, it requires a greater abstraction where the material's and energy's features are symbolized by mathematical symbols. Further, many people have no excellent mathematical abstraction skills. Thus, physical phenomena are frequently distorted by the individual assumption that fills the understanding gap. Similar to the experimental approach, mathematical formula mostly also in the form of equations that unable to directly demonstrate a dynamic phenomenon, such as heat flow. These two approaches are scientific and critical parts of the scientific method that can be accounted for [5]. The approaches include observation of a natural event or phenomena with regularity pattern, hypothesis, and comparison to fundamental models or laws in the form of a mathematical formula.

The current advancement of computing and electronics may ease complex digital simulations. Digital promises a better visualization of physical phenomena, including the heat flow. Other than that, a simulator acts as the visual and counting device. Through this digital simulation, heat flow phenomena can be clearly visualized to help someone's inability to imagine the phenomena. Besides, the estimation results can be used to validate mathematical models so that the academicians' or students' understanding of physical phenomena are also improved.

This part is essential since most of the physics learning mostly only emphasize on students completing mathematical exercises with a limited practice period. Consequently, it erases the essential aspect of students' physical phenomena understanding. Digital simulation-based learning is the latest physical learning method that adapts the visual learning style for students in this digital era. Besides, in the current normal situation, this learning can aid students due to the reduced face-to-face learning and laboratory experiment.

This study investigates the digital simulation for heat transfer material using Energy2D software [6]. The learning includes the basic concept of heat conduction, thermal diffusion concept to expand the understanding of heat conduction on solids, practical aspect from heat conduction on solids, and heat conduction on a solid composite material. The basic principle of thermal physics is thermodynamics laws [7], [8].

The zeroth law of thermodynamics explains that thermal equilibrium of two or more items in a closed system through a thermal contact. This law states that if two systems are in thermal equilibrium of the third, they are in the same equilibrium [7], [8].

$$
\mathrm{A}=\mathrm{B}, \mathrm{B}=\mathrm{C} \text {, then } \mathrm{A}=\mathrm{C}
$$

Figure 2 illustrates the thermal equilibrium of three items, A, B, and C, marked by the same temperature. Before the thermal equilibrium, the heat transfer may occur through conduction, convection, and radiation mode. 


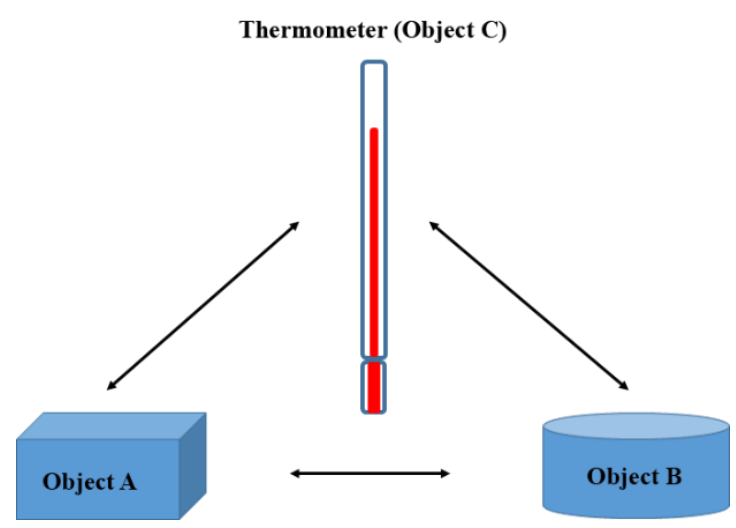

Figure 2. Thermal equilibrium of three items.

Meanwhile, the first law of thermodynamics is related to energy preservation. This law declares that the inner energy transformation of a closed thermodynamics system is equal to the total energy supplied to the system and the works performed within the system. In short, this law mention that energy cannot be formulated or abolished, it only transforms into different forms of energy. For the purpose of thermodynamics, a more specific quantitative explanation is required [7], [8]

$$
Q=\Delta U+W
$$

in which $Q, \Delta U$, and $W$ represent the total heat flow, inner energy changes, and work done by the system, respectively, all of them are in the joule (J) unit. $Q$ heat is the thermal energy that flows due to the temperature differences. In other words, once there is a temperature difference (among two things, a thing and environment or things' position in an environment), then the heat transfer occurs. The inner energy $(U)$ is the energy of a thing caused by the temperature rate. A higher temperature rate means a more considerable inner energy, and vice versa. Heat $(Q)$ is positive if it enters a system (or the other way around), $\Delta U$ is positive is the inner energy improves (or the other way around), and $W$ is positive if the system performs a work.

The second law of thermodynamics explains the natural condition of one-way heat flow, where the heat flows from the high-temperature item to another item with a lower temperature. In other words, the heat unable to spontaneously flow from an item with low temperature to the other items with higher temperatures with no work performed [7], [8]. The temperature difference between solids results in conduction heat flow. Besides, in different steady-state, the conduction heat transfers generally occur in solid material can be formulated as in Formula 3 [9]

$$
\frac{Q}{t}=\frac{k A \Delta T}{L}
$$

with $Q, k, A, \Delta T, L$, and $t$ that represent the total heat flow, thermal conductivity, item's cross-sectional area, temperature difference, item's length, and time. According to the thermal conductivity value, known as material classification as thermal conductor (the high value of thermal conductivity) and thermal insulator (the small value of thermal conductivity). Generally, metal is the thermal conductor.

The heat received by an item is related to the temperature change experienced by the item, as explained in the following mathematical formula [10]

$$
Q=m c \Delta T
$$

with $m, c$, and $\Delta T$ symbolize mass, specific heat, and temperature difference, respectively. The heat related to temperature difference is known as sensible heat. Other than sensible heat, the item's heat may also relate to the occurring transitional phase, such as solid-liquid, liquid-gas, or solid-gas, that is popular as latent heat [10]

$$
Q=m L
$$

with $L$ means latent heat. 
Table 1. The thermophysical characteristics of some materials [9], [11], [12].

\begin{tabular}{lccc}
\hline Material & $\begin{array}{c}\text { Density } \rho \\
\left(\mathrm{kg} / \mathrm{m}^{3}\right)\end{array}$ & $\begin{array}{c}\text { Specific Heat } c \\
(\mathrm{~J} /(\mathrm{kg} \cdot \mathrm{K}))\end{array}$ & $\begin{array}{c}\text { Thermal Conductivity } \kappa \\
(\mathrm{W} /(\mathrm{m} \cdot \mathrm{K}))\end{array}$ \\
\hline Air & 1.276 & 1006 & 0.02 \\
\hline Water & 1000 & 4180 & 0.6 \\
\hline Copper metal & 8954 & 380 & 386 \\
\hline Steel/iron metal & 7874 & 449 & 45 \\
\hline Brick/concrete & $1600-2000$ & $879-974$ & $\sim 0.60-0.73$ \\
\hline Wood/multiplex & $\sim 300-700$ & $1300-2400$ & $\sim 0.10-0.19$ \\
\hline Glass & $2400-2800$ & $750-840$ & 0.87 \\
\hline Ceramic & 2000 & 1000 & 0.9 \\
\hline Zinc & 7144 & 401 & 115 \\
\hline
\end{tabular}

As the standard definition, an item's mass is related to the objects' density and volume

$$
\rho=\frac{m}{V}
$$

meanwhile, according to Formula 4, specific heat is the amount of heat per the object's mass required to improves the temperature by one unit

$$
c=\frac{Q}{m \Delta T}
$$

The thermal features of several materials, including material type, density parameter, thermal capacity, and thermal conductivity, are presented in Table 1.

\section{Method}

Energy2D program is a multiphysics interactive simulation program that model conduction, convection, and radiation heat transfer, as well as the incorporation with particle dynamics. This program allows the user to design a computing experiment to test a scientific hypothesis or solve technical problems with no complex mathematics [13]. For the simulation with Energy2D, some parameters related to the object and environment need to be adjusted. The object's parameters involve geometry, thermal features, optic, and mechanic. At the same time, the environment's parameter consists of general features, medium, light beam, particle, and boundaries. Generally, all of those parameter values require adjustments before the simulation to obtain a proper natural condition. Table 2 shows the environment parameter values frequently used, primarily for heat conductor simulation investigated in this study. Mainly, the air thermal conductivity was set low to minimize the conduction to the air. The Dirichlet boundary conditions declare that a constant temperature rate, while Neumann boundary conditions state constant heat flux [14].

\begin{tabular}{|c|c|c|}
\hline Characteristics & Parameter & Value \\
\hline \multirow{4}{*}{ Medium } & Temperature $\left({ }^{\circ} \mathrm{C}\right)$ & 25 \\
\hline & Thermal conductivity $\left(\mathrm{W} /\left(\mathrm{m} .{ }^{\circ} \mathrm{C}\right)\right)$ & 0.000000001 \\
\hline & Heat capacity $\left(\mathrm{J} /\left(\mathrm{kg} .{ }^{\circ} \mathrm{C}\right)\right)$ & 1000 \\
\hline & Density $\left(\mathrm{kg} / \mathrm{m}^{3}\right)$ & 1.2 \\
\hline \multirow{5}{*}{ Particle } & Number of Particle & 0 \\
\hline & Acceleration due to gravity $\left(\mathrm{m} / \mathrm{s}^{2}\right)$ & 9.8 \\
\hline & Braking coefficient $(\mathrm{kg} / \mathrm{s})$ & 0.01 \\
\hline & Hardness & 1 \\
\hline & Thermophoretic coefficient $\left(\mathrm{kg}^{2} \mathrm{~m}^{2} / \mathrm{s}^{2}\right)$ & 0 \\
\hline \multirow{5}{*}{$\begin{array}{l}\text { Boundary } \\
\text { Condition }\end{array}$} & Thermal boundary & Neumann \\
\hline & Upper boundary heat flux $\left({ }^{\circ} \mathrm{C} / \mathrm{m}\right)$ & 0 \\
\hline & Right boundary heat flux $\left({ }^{\circ} \mathrm{C} / \mathrm{m}\right)$ & 0 \\
\hline & Lower boundary heat flux $\left({ }^{\circ} \mathrm{C} / \mathrm{m}\right)$ & 0 \\
\hline & Left boundary heat flux $\left({ }^{\circ} \mathrm{C} / \mathrm{m}\right)$ & 0 \\
\hline
\end{tabular}

Table 2. General environment model variable for the simulation process. 


\section{Results and Discussion}

An observation on the metal beam that was heated on its left side at constant temperature reveals onedimension heat conduction (horizontal). After some time, the temperature of the objects' right side was measured, with the initial temperature at $0{ }^{\circ} \mathrm{C}$. The simulation of heat conduction on an object using Energy2D software is illustrated in Figure 3 to 6 . The object's thermal parameter was changed following the conduction parameter simulation. Substantially, for all of the heat conduction simulation, the absorption coefficient value was 1 , the optical properties in Table 2 , where all objects perfectly absorb.

The blue lines in Figure 7 are the current flow of the heat flux that past the object, as an analogy of the water stream or current stream along the conductive wire. Figure 7 reveals that the heat conduction is in line with the thermal conductivity, cross-sectional area, and temperature difference. However, it is inversely proportional to the objects' length. Thus, a more substantial thermal conductivity $\left(k_{2}\right)$, greater cross-sectional area $\left(A_{2}\right)$, and higher temperature different $\left(\Delta T_{2}\right)$ produce faster heat conduction, as marked by the temperature value at a specific time.

Based on the four factors that affect conduction, the object's cross-sectional area and length are the geometry factor. At the same time, the thermal conductivity belongs to the thermophysical factor with an intrinsic feature. The heat flow through metal can be directly illustrated as the electrical flow on conductive wire or water stream in the river, in which the thermal conductivity is analogous to the electrical conductivity or fluidity as the measurement of how easy the fluid flows that is the opposite of viscosity [15], [16]. The more considerable thermal conductivity or the electrical conductivity or the fluidity accelerates the heat, electrical, or water flow, and vice versa.

Other than thermal conductivity, for the heat conduction on material other than metal, the other physical parameter, such as thermal diffusivity (defined in Formula 8), should be considered.

$$
\alpha=\frac{k}{\rho c}
$$

in which $\rho$ is the object's density, and $c$ means the object's heat specific [9]. Disfussity marks the diffusion process of the heat, affected by density and thermal capacity. Figure 7 illustrates the heat conduction on copper and wood with the value of the thermophysic parameter that is presented in Table 1. The results demonstrate the effect of the thermal diffusivity parameter, such as thermal conductivity, density, and object's thermal capacity.

Table 3. Object's parameter other than the simulation parameter.

\begin{tabular}{lll}
\hline \multicolumn{1}{c}{ Properties } & \multicolumn{1}{c}{ Parameter } & Value \\
\hline \multirow{3}{*}{$\begin{array}{l}\text { Source }(\text { not } \\
\text { constant } \\
\text { temperature })\end{array}$} & Temperature $\left({ }^{\circ} \mathrm{C}\right)$ & 0 \\
\cline { 2 - 3 } & Temperature coefficient $\left(1 /{ }^{\circ} \mathrm{C}\right)$ & 0 \\
\cline { 2 - 3 } & Referenced temperature $\left({ }^{\circ} \mathrm{C}\right)$ & 0 \\
\cline { 2 - 3 } Therma & Wind speed $(\mathrm{m} / \mathrm{s})$ & 0 \\
\cline { 2 - 3 } & Thermal capacity $\left(\mathrm{J} / \mathrm{kg} .{ }^{\circ} \mathrm{C}\right)$ & 0 \\
\cline { 2 - 3 } & Density $\left(\mathrm{kg} / \mathrm{m}^{3}\right)$ & 1000 \\
\hline \multirow{3}{*}{ Optic } & Absobtion coefficient & 000 \\
\cline { 2 - 3 } & Transmission coefficient & 0 \\
\cline { 2 - 3 } & Reflection coefficient & 0 \\
\cline { 2 - 3 } & Emission coefficient & 1 \\
\hline Mecanic & Elasticity & \\
\hline
\end{tabular}




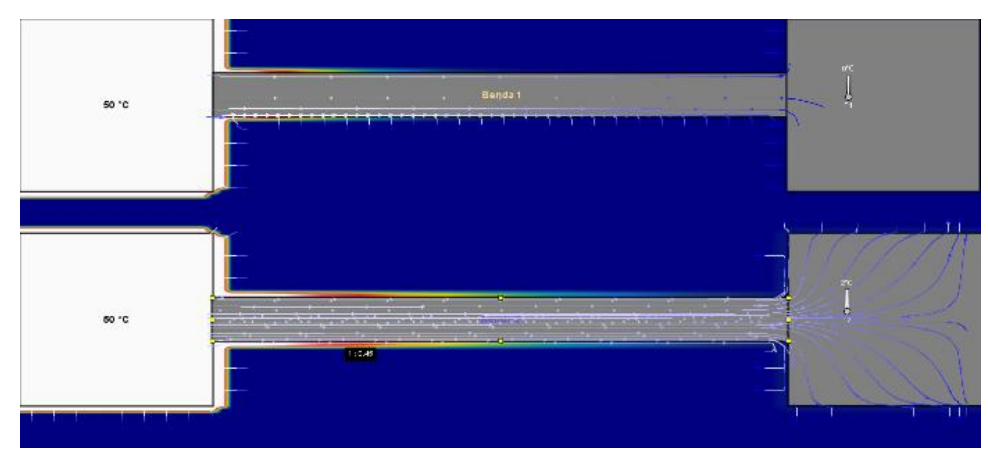

(a)

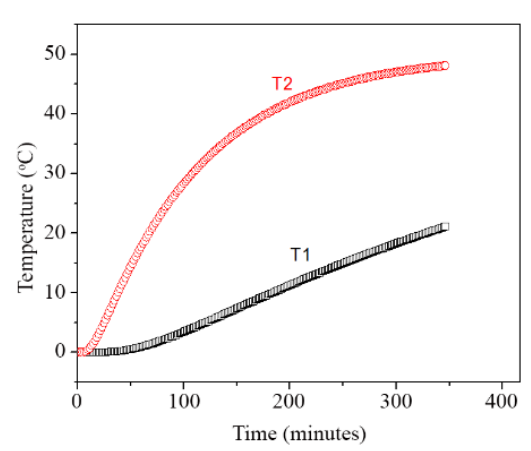

(b)

Figure 3. (a) Simulation process with thermal conductivity parameter of $k_{1}=0,1 \mathrm{~W} / \mathrm{m} . \mathrm{K}$ and $k_{2}=0,5 \mathrm{~W} / \mathrm{m} . \mathrm{K}$; (b) Chart of the obtained object's temperature.

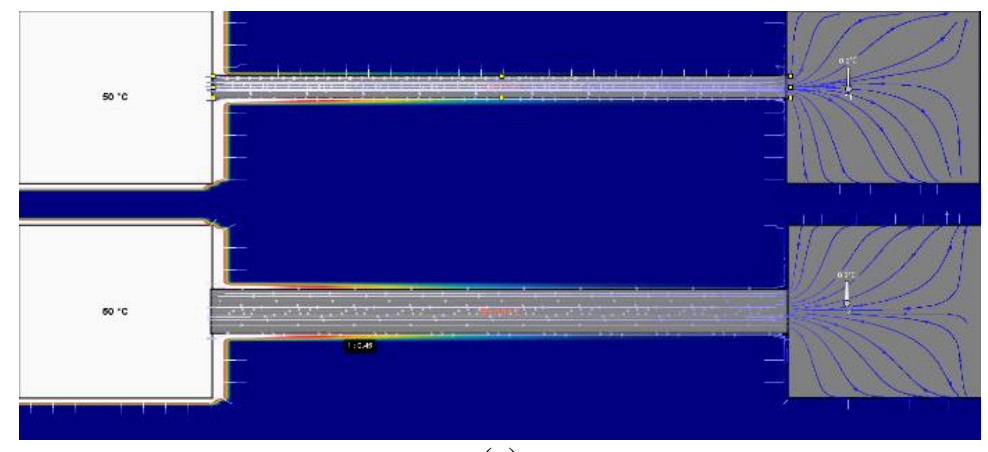

(a)

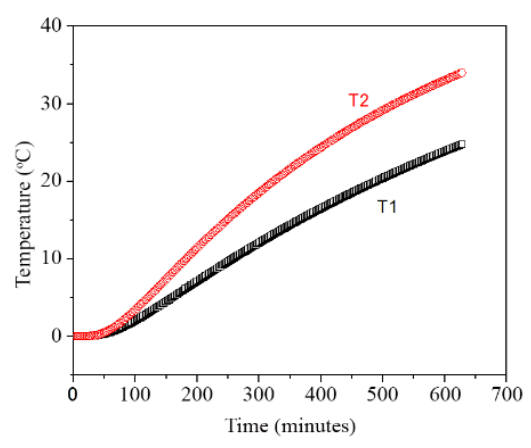

(b)

Figure 4. (a) Simulation process with object's cross-sectional area of $A_{1}=0,005 \mathrm{~m}^{2}$ and $A_{1}=0,010 \mathrm{~m}^{2}$; (b) Chart of the obtained object's temperature.

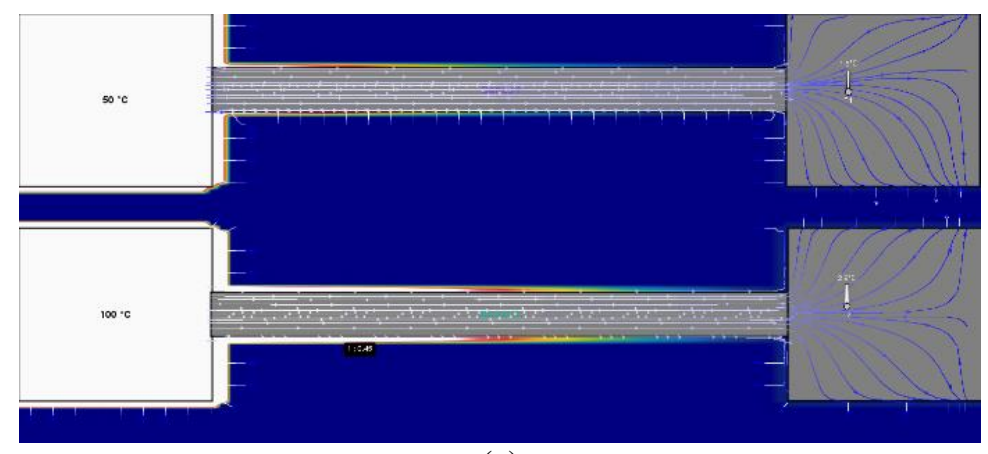

(a)

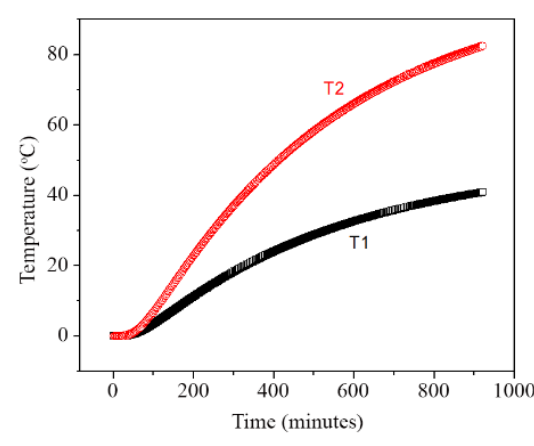

(b)

Figure 5. (a) Simulation process with temperature difference parameter of $\Delta T_{1}=50^{\circ} \mathrm{C}$ and $\Delta T_{2}=100^{\circ} \mathrm{C}$; (b) Chart of the obtained object's temperature.

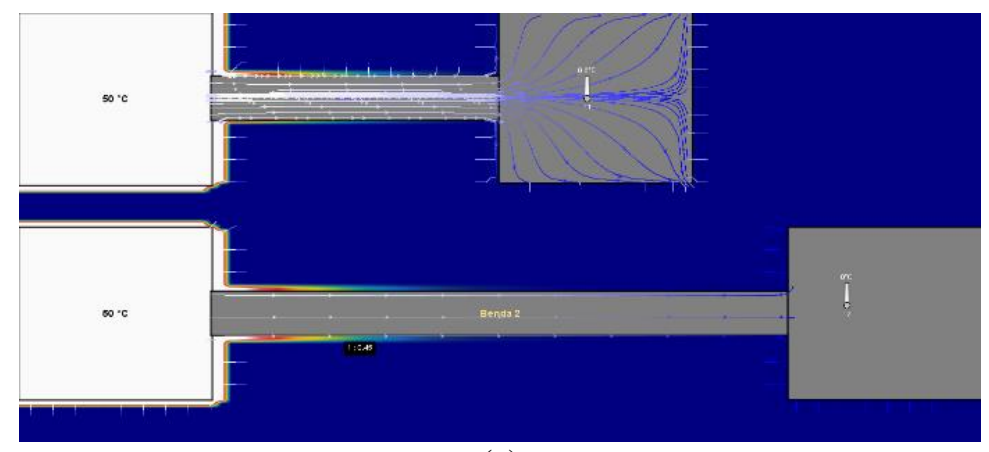

(a)

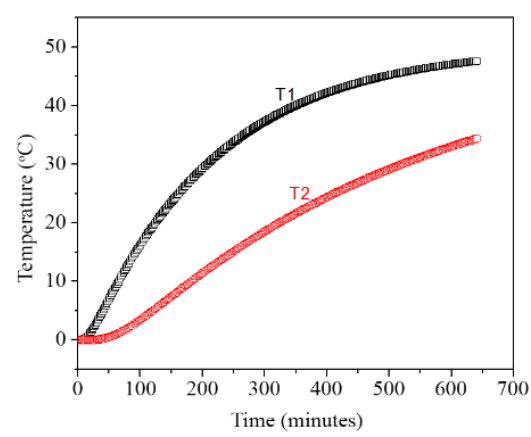

(b)

Figure 6. (a) Simulation process with object's length parameter of $L_{1}=0,03 \mathrm{~m}$ and $L_{2}=0,06 \mathrm{~m}$; (b) Chart of the obtained object's temperature. 


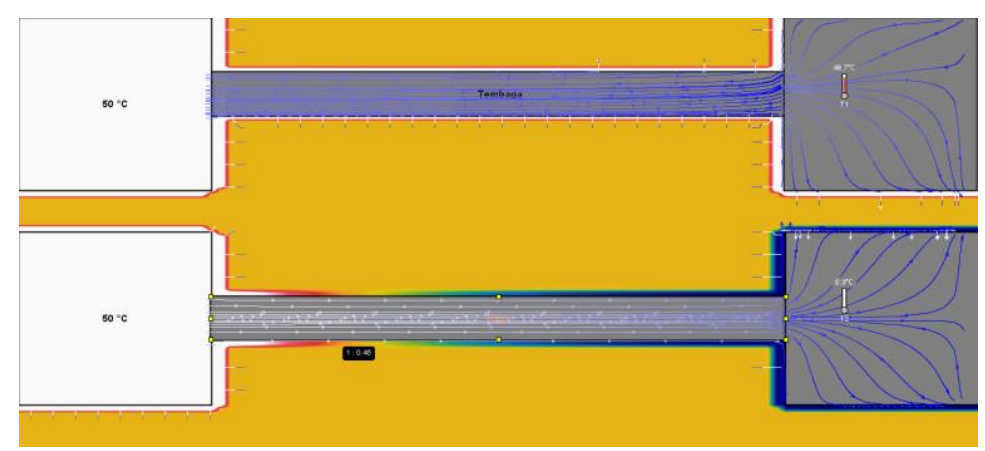

(a)

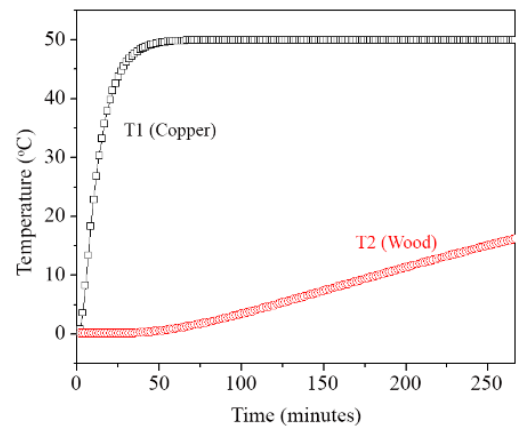

(b)

Figure 7. (a) Heat conduction on copper (above) and wood (below) that shows the effect of thermal conductivity, density, and object's heat capacity parameters; (b) Chart of the obtained object's temperature.

Based on Figure 7, the same dimension copper and woods heated at the same temperature of 50 ${ }^{\circ} \mathrm{C}$ constantly at the left side result in the same $50{ }^{\circ} \mathrm{C}$ temperature at the right side, at a relatively short period. The steady condition of copper spontaneously occurs, as shown by the heat flow at constant temperature (no changes across the time). In contrast, the heat flow on the wood is dominated by the transient situation (the opposite of steady), as presented by the changing temperature at different times. According to the thermal diffusivity parameter, the heat conduction on the copper can be picturized as water flow without resistance or electrical flow along the conductive wire. At the same time, the heat flow on wood (non-conductor material) can be illustrated as a diffusion process, such as water flow on a porous object.

In the practical application, a combination of object's thickness $(L)$ and thermal conductivity $(k)$ produces R constant, known as thermal resistance (R-value) [9], [17], [18]

$$
R=\frac{L}{k A}
$$

Or in contrast, as a thermal transmittant ( $U$-value), so that the heat conduction formula can be rewritten as follow.

$$
\frac{Q}{t}=\frac{\Delta T}{R}
$$

If the heat flow is analogous to electrical flow $I(I=\Delta Q / \Delta t)$ and the temperature difference at the ends of the conductor as $\Delta V(=\Delta T)$, then the heat conduction formula can be written as follow.

$$
\Delta V=I R \quad \text { or } I=\frac{\Delta V}{R}
$$

It is also known as Ohm law for thermal, as the analogy for the Ohm law for the electricity that explains the electrical flow through an electrical conductor. In other words, the heat flow rate through a conductor is equal to the temperature difference that becomes the driving force of the heat flow and inversely proportional to the conductor resistance.

As for the fact, a building's wall generally comes from a combination of some materials with different $R$-value. Similar to the combination of resistors in the electric current circuit, the combination of thermal resistance can be modelled in the series or parallel circuits. Figure 8 illustrates the thermal resistance series combination, as a sandwich wall from layers of materials with different $R$-value and same A cross-sectional area.

In the stationery situation, all heat that comes to layer will be passed on the other layers with no heat being absorbed by the layers or the wall.

$$
\frac{\Delta Q}{\Delta t}=\left(\frac{k A}{L}\right)_{A}\left(T_{1}-T_{2}\right)=\left(\frac{k A}{L}\right)_{B}\left(T_{2}-T_{3}\right)=\left(\frac{k A}{L}\right)_{C}\left(T_{3}-T_{4}\right)
$$




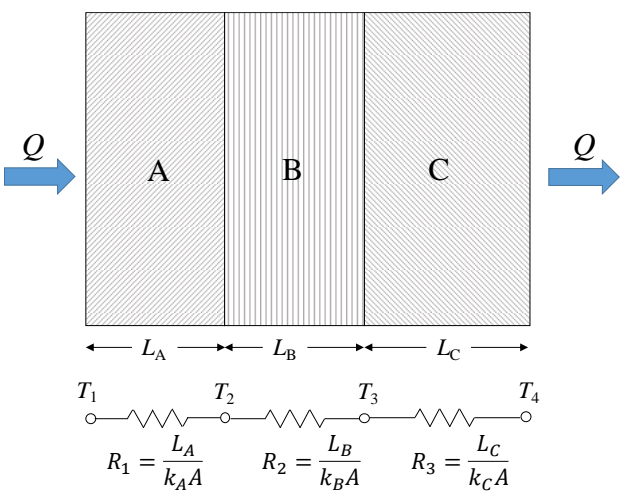

Figure 8. Three thermal conductors layers that are connected in a series circuit with the same A cross-sectional area.

By an elimination on $T_{2}$ and $T_{3}$ then,

$$
\frac{\Delta Q}{\Delta t}=\frac{T_{1}-T_{4}}{(L / k A)_{A}+(L / k A)_{B}+(L / k A)_{C}}
$$

Further, the equivalent $\mathrm{R}$-value definition for series resistance circuits is

$$
R_{S}=R_{A}+R_{B}+R_{C}
$$

then, it can be written as

$$
\frac{\Delta Q}{\Delta t}=\frac{\Delta T}{R_{S}}
$$

in which $\Delta T$ is the temperature difference through the overall wall that is frequently called a potential temperature.

The parallel circuits of thermal resistance are illustrated in Figure 9. The heat flow from each surface can be estimated, separately, to obtain the heat flow through every external surface of a building exposed to air (wall, floor, door, and window). After that, the results are summed up due to the same temperature difference.

Based on the notation defined above that

$$
\frac{Q}{t}=\left(\frac{Q}{t}\right)_{1}+\left(\frac{Q}{t}\right)_{2}+\left(\frac{Q}{t}\right)_{3}=\frac{T_{1}-T_{2}}{(L / k A)_{A}}+\frac{T_{1}-T_{2}}{(L / k A)_{B}}+\frac{T_{1}-T_{2}}{(L / k A)_{C}}=\frac{T_{1}-T_{2}}{R_{p}}
$$

the equivalent thermal resistance of all resistances in the parallel circuit can be defined as follow.

$$
\frac{1}{R_{p}}=\frac{1}{R_{A}}+\frac{1}{R_{B}}+\frac{1}{R_{C}}
$$

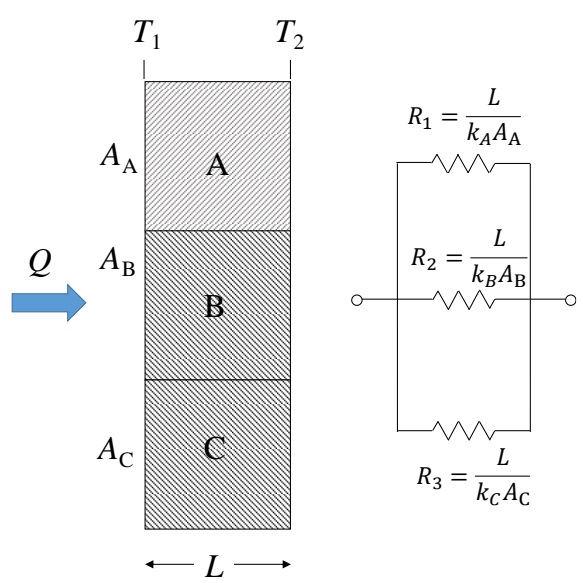

Figure 9. Three conductors connected in a parallel circuit, with different R-value and A cross-sectional area. The driving force of the heat flow is temperature difference of $\Delta T=T_{2}-T_{1}$ at both sides in the opposites of the conductor. 
Thermal resistance simulation in series circuits using Energy2D software is presented in Figure 10; meanwhile, thermal resistance in the parallel circuit is shown in Figure 11. According to the graphics in Figures 10 and 11, there is a significant difference between the thermal resistance in series and parallel circuits. In the series circuit, other than affected by the thermal conductivity parameter, the temperature graphic toward time is also dominantly influenced by the distance between the wall layer to the heat source. The farthest wall layer from the heat source produces the smallest temperature increase graphic, compared to other layers located nearer to the heat source. It shows the delay in heat flow, at the same time. In the parallel circuit, with the same sensory position, the regularly rising temperature is only affected by the thermal conductivity of the wall layer. A more considerable thermal conductivity carries a faster temperature increase than the smaller thermal conductivity. In fact, the convection and radiation heat transfer should also be calculated.

The concept of heat flow is critical for daily human life, specifically for houses or buildings for human habitation. The thermal comfort in a room or building is extremely determined by the thermal behavior of the building's components. The heat absorption and release are generally dominated by the wall, floor, and roof cover, as determined by their thermophysical parameter values [1], [19]. Additionally, Figure 12 illustrates room air temperature measurement on typical Indonesia housing with a different roof, such as concrete, wood, and a tin roof. The simulation was conducted in 12 hours for a few days to identify the effect of heat absorption and release in different roof material. In this simulation, only conduction heat transfer being observed (both intrinsic material conduction and air conduction) and radiation.

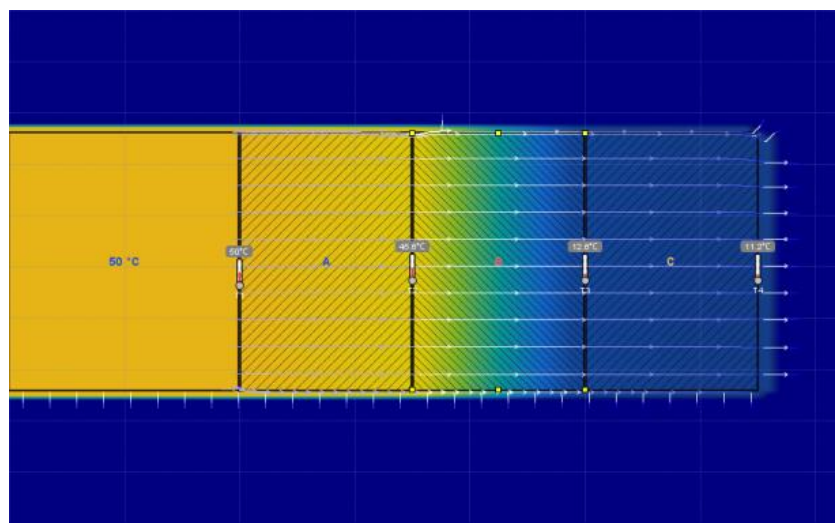

(a)

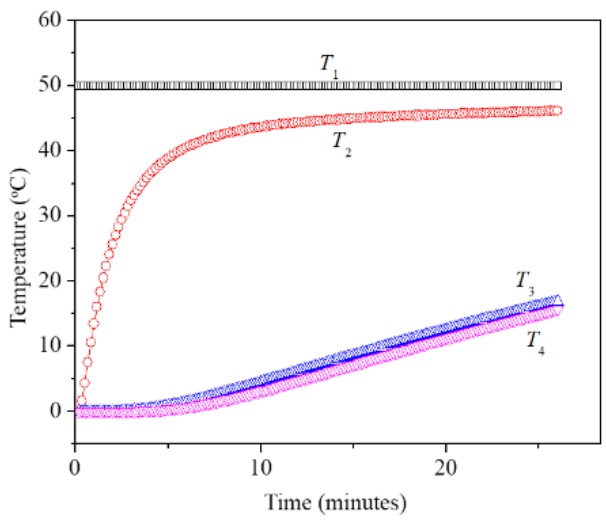

(b)

Figure 10. (a) Three thermal resistances in series circuit with $k_{\mathrm{A}}=1,0 \mathrm{~W} / \mathrm{m} . \mathrm{K}, k_{\mathrm{B}}=0,5 \mathrm{~W} / \mathrm{m} . \mathrm{K}$, and $k_{\mathrm{C}}=0,1 \mathrm{~W} / \mathrm{m} . \mathrm{K}$; (b) Chart of the obtained object's temperature.

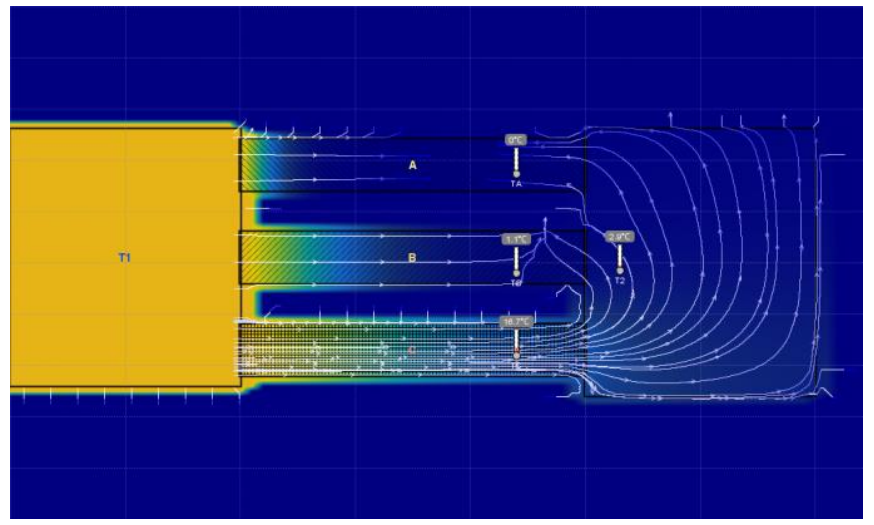

(a)

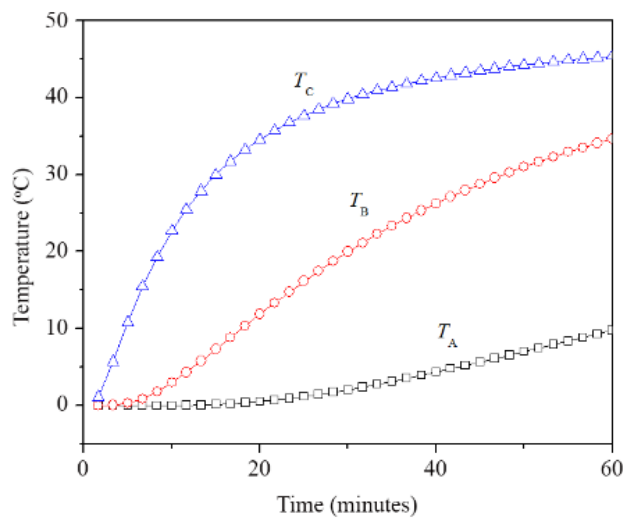

(b)

Figure 11. (a) Three thermal resistances in series circuit with $k_{\mathrm{A}}=0,01 \mathrm{~W} / \mathrm{m} \cdot \mathrm{K}, k_{\mathrm{B}}=0,1 \mathrm{~W} / \mathrm{m} \cdot \mathrm{K}$, and $k_{\mathrm{C}}=0,5 \mathrm{~W} / \mathrm{m} . \mathrm{K}$; (b) Chart of the obtained object's temperature. 


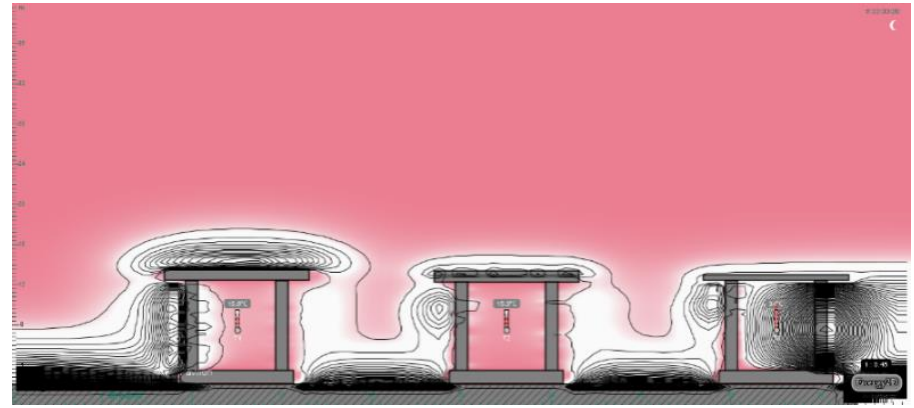

(a)

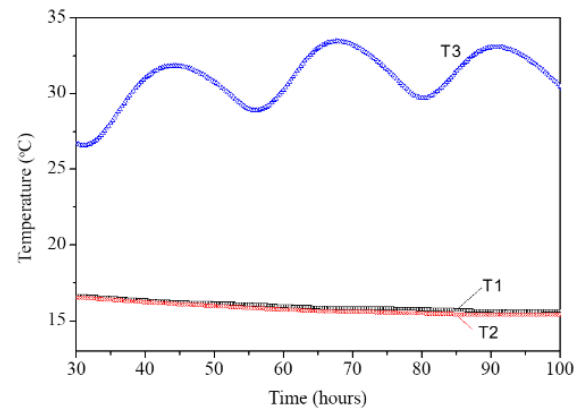

(b)

Figure 12. (a) Simulation of room air temperature measurement on typical Indonesia housing with three different roofs, concrete (left, T1), wood (middle, T2), and tin roof (right, T3); (b) Graphics of room air temperature of T1, T2, and T3 measured at the middle of each room.

According to the simulation, the concrete and wood roof has relatively stable room air temperature than the tin roof. The variation of room air temperature (maximum-minimum) for a tin roof is $4.5{ }^{\circ} \mathrm{C}$. This comparatively wide temperature variation causes inconveniences for the resident. A manipulation on roof cover material decreases the heat penetration during the day. The frequently used roof cover manipulation technique is by reflecting the sun radiation landed on the roof surface by adding the reflecting layer and roof ventilation system to release the heat on the roof structure [20].

In addition, some experts use mitigation techniques to reduce the air temperature during the day in a room through daytime heat storage and nigh time heat release technique using phase change material (PCM) [10], [21]. One of the local PCM that can be utilized in a tropical climate is coconut oil [22], [23], which can be used as an additional thermal mass in a room [24]. The use of coconut oil PCM panels in a room, however, should consider the daily weather [23] and the room air circulation [24].

\section{Conclusion}

Heat conduction is a thermal diffusion process that is generally affected by the thermophysical parameter, such as the material's thermal conductivity, density, and thermal capacity. For metal material (conductor) with relatively huge thermal conductivity and small heat specific, the tremendous thermal diffusion can be analogous to water stream along the pipe or electrical flow along the conductive wire. Additionally, for non-metal material, such as wood, glass, brick, or concrete with relatively small thermal conductivity value and substantial specific heat, the thermal diffusion occurs slowly, as water stream in the soil that goes through the pores or gaps between soil particles.

The application of the thermal conduction concept on building generally uses thermal resistance (R-value) parameter or thermal transmittance (U-value) that determine the material's dimension and the design of the building's layer material. The design decides the direction and amount of heat flow in the building wall. In practice, the thermal resistance can be arranged in a series or parallel circuit, as well as in the combination of them. According to the Ohm law for electric current analogy, the equivalent resistance of the circuits of thermal resistance can be estimated.

The digital simulation using the Energy2D program helps the understanding of the entire thermal conduction phenomena, both from scientific and applicative technique sides. Other than beneficial for students learning in schools during this digital era, digital simulation is expected to aid the physic learning in the 'new normal' era. Excellent comprehension of physical phenomena is required for the development of building design or material manipulation for human convenience and environment conservation.

\section{References}

[1] T. Kusuda, "Fundamentals of Building Heat Transfer," J. Res. Nation. Bureau Stand., vol. 82, no. 2, pp. 97-106, 1977.

[2] Í. Yüksek, "The Evaluation of Building Materials in Terms of Energy Efficiency," Period. Polytechn. Civ. Eng., vol. 59, no. 1, pp. 45-58, 2015.

[3] M. A. Kamal, "Material Characteristics and Building Physics for Energy Efficiency," Key Eng. Mat., vol. 666, pp. 77-87, 2016. 
[4] S. Wonorahardjo et al., "Characterising Thermal Behaviour of Buildings and Its Efect on Urban Heat Island in Tropical Areas," Int. J. Energy and Envir. Eng., vol. 11, no. 1, pp. 129-142, 2020.

[5] J. Trefill and R.M. Hazen, The Sciences: An Integrated Approach, 6th ed., New Jersey: John Wiley \& Sons, 2010.

[6] C. Xie, "Interactive Heat Transfer Simulation for Everyone," J. Phys. Teach., vol. 50, no. 4, pp. 237-240, 2012.

[7] M. W. Zemansky and R. H. Dittman, Heat and Thermodynamics, 7th ed., New York: McGrawHill, 1997.

[8] D. Halliday, R. Resnick, and J. Walker, Fundamentals of Physics, 10th ed., Extended ed., New Jersey: Wiley, 2014.

[9] F. Kreith, R. M. Manglik, and M. S. Bohn, Principles of Heat Transfer, 7th ed., Massachusetts: Cengage Learning Inc., 2011.

[10] H. Mehling and L. F. Cabeza, Heat and Cold Storage with PCM, Berlin: Springer-Verlag, 2008.

[11] G. Wei et al., "Selection Principles and Thermophysical Properties of High Temperature Phase Change Materials for Thermal Energy Storage: A Review," Renewable and Sustainable Energy Rev., vol. 81, no. 2, pp. 1771-1786, 2018.

[12] J. J. Valencia and P. N. Quested, "Thermophysical Properties," ASM Handbook, vol. 15, pp. 468481, 2008

[13] Charles Xie, "Interactive Heat Transfer Simulations for Everyone," The Phys. Teach., vol. 50, no. 4, pp. 237-240, 2012.

[14] M. C. Wendl, Theoretical Foundations of Conduction and Convection Heat Transfer, Saint Louis: The Wendl Foundation, 2012.

[15] B. R. Munson et al., Fundamentals of Fluid Mechanics, 6th ed., New Jersey: John Wiley \& Sons, 2009.

[16] L. V. Heilbrunn, "The Viscosity of Protoplasm," in Protoplasmatologia Handbuch der Protoplasmaforschung, L. V. Heilbrunn and F. Weber, Vienna: Springer-Verlag, 1958.

[17] S. Wonorahardjo and I. M. Sutjahja, Bangunan Gedung Hijau untuk Daerah Tropis (Teori, Konsep, dan Penerapan), Bandung: ITB Press, 2018.

[18] Y. Salu, Physics for Architects, Pennsylvania: Infinity Publishing, 2003.

[19] J. Straube, "Thermal Control in Buildings," Build. Sci. Digest, vol. 11, pp. 1-12, 2006.

[20] S. Tong et al., "Thermal Performance of Concrete based Roofs in Tropical Climate," Energy and Build., vol. 76, pp. 392-401, 2014.

[21] A. Madad, T. Mouhib, and A. Mouhsen, "Phase Change Materials for Building Applications: A Thorough Review and New Perspectives," Buildings, vol. 8, no. 5, p. 63, 2018.

[22] S. Wonorahardjo et al., "Potential of Thermal Energy Storage using Coconut Oil for Air Temperature Control," Buildings, vol. 8, no. 8, p. 95, 2018.

[23] S. Wonorahardjo et al., "Adjustment of Indoor Temperature using Internal Thermal Mass under Different Tropical Weather Conditions," Sci. Technol. Built Envir., vol. 26, no. 2, pp. 115-127, 2020.

[24] S. Wonorahardjo, I. M. Sutjahja, and D. Kurnia, "Potential of Coconut Oil for Temperature Regulation in Tropical Houses," J. Eng. Phys. Thermophys., vol. 92, no. 1, pp. 80-88, 2019. 